Odjel za polimere

Pododbor za nazivlje (terminologiju) polimera

Nomenklatura i terminologija iz područja polimera i polimernih materijala

\section{Definicije naziva povezanih s pojedinačnim makromolekulama, makromolekulskim nakupinama, polimernim otopinama i amorfnim polimernim tvarima (II. dio)}

\author{
Preporuke IUPAC 2014. \\ Preporuke HDKI i HKD 2016.
}

Pripravila radna skupina u sastavu:

Robert Stepto**, Taihyun Chang, Pavel Kratochvíl, Michael Hess,

Kazuyuki Horie, Takahiro Sato i Jiři Vohlídal

Preveo:

Marko Rogošić*

Sveučilište u Zagrebu, Fakultet kemijskog inženjerstva i tehnologije
DOI: $10.15255 /$ KUI.2015.049b

KUI-22/2017

Nomenklaturni prikaz

Prispjelo 30. studenoga 2015.

Prihvaćeno 18. svibnja 2016.

\title{
|| Sažetak
}

Ovaj dokument definira nazive povezane sa svojstvima pojedinačnih makromolekula, makromolekulskih nakupina, polimernih otopina i amorfnih polimernih tvari. U odjeljku o polimernim otopinama i amorfnim polimernim tvarima razmatraju se opće i termodinamičko nazivlje, razrijeđene otopine, fazno ponašanje, transportna svojstva, metode raspršenja svjetlosti i separacijske metode. Preporuke su revizija i proširenje nazivlja IUPAC-a objavljenog 1989., koje se ticalo pojedinačnih makromolekula, makromolekulskih nakupina i razrijeđenih polimernih otopina. Uvedeni su novi nazivi koji pokrivaju glavna teorijska i eksperimentalna saznanja do kojih se u međuvremenu došlo. Polielektroliti nisu uključeni.

\section{\| Ključne riječi}

Amorfni polimeri, polimerne mase, IUPAC-ov Odjel za polimere, makromolekulske nakupine, makromolekule, fazno ponašanje polimera, polimerne otopine, termodinamika polimera, svojstva raspršenja svjetlosti, separacijske metode, transportna svojstva

\section{Sadržaj}

3. Polimerne otopine i amorfne polimerne tvari 267

3.1. Opći i termodinamički nazivi 267

3.2. Razrijeđene otopine 269

3.3. Fazno ponašanje 270

3.4. Transportna svojstva 272

Literatura 277

Summary 278

* Prof. dr. sc. Marko Rogošić, mrogosic@fkit.hr

** Autor za korespondenciju: Robert Stepto, School of Materials, The University of Manchester, Manchester M1 7HS, UK, e-mail: rftstepto@gmail.com.

*** Izvornik: Robert Stepto, Taihyun Chang, Pavel Kratochvíl, Michael Hess, Kazuyuki Horie, Takahiro Sato, Jiř̌ Vohlídal, Definitions of terms relating to individual macromolecules, macromolecular assemblies, polymer solutions, and amorphous bulk polymers (IUPAC Recommendations 2014), Pure Appl. Chem. 87(1) (2015) 71-120.

Recenzenti: Davor Kovačević, Branko Kunst, Ivan Šmit, Valerije Vrček

\section{Polimerne otopine i} amorfne polimerne tvari

\subsection{Opći i termodinamički nazivi}

3.1.1. razrijeđena otopina (u polimernoj znanosti) (dilute solution)

Otopina kod koje je zbroj volumena domena zauzetih otopljenim makromolekulama ili česticama znatno manji od ukupnog volumena otopine.

Napomena 1: Naziv "domena" odnosi se na najmanji volumen koji sadrži makromolekulu ili otopljenu česticu u svome prosječnom obliku.

Napomena 2: Ova je definicija konzistentna s onom iz "Zlatne knjige". ${ }^{3} \mathrm{U}$ polimernoj se znanosti prednost daje upravo ovoj definiciji zbog važnosti koncepta makromolekulskih domena. 
3.1.2. prijelazna koncentracija, $c^{*}$, jedinica: $\mathrm{g} \mathrm{cm}^{-3}$ ili $\mathrm{SI}$ jedinica: $\mathrm{kg} \mathrm{m}^{-3}$ (cross-over concentration)

koncentracija preklapanja $^{\mathrm{n}}$ (overlap concentration)

Koncentracija pri kojoj je zbroj volumena domena zauzetih otopljenim makromolekulama ili česticama približno jednak ukupnom volumenu otopine.

Napomena 1: Za značenje naziva "domena" vidi definiciju 3.1.1., napomenu 1.

Napomena 2: Prijelazna koncentracija nije jednoznačno određena jer različite mjerne tehnike daju različite vrijednosti.

Napomena 3: U fizikalnoj kemiji oznaka c odnosi se obično na množinsku koncentraciju, ali se u polimernoj znanosti općenito rabi za masenu koncentraciju. Molarna masa polimera opisuje se funkcijom raspodjele umjesto jednom vrijednošću, stoga se množinska koncentracija za polimerne otopine ne može precizno definirati.

\subsection{3. polurazrijeđena otopina (semi-dilute solution)}

Polimerna otopina u koncentracijskom području pri kojem se domene zauzete otopljenim makromolekulama ili česticama počinju preklapati.

Napomena: Otopine se počinju vladati poput polurazrijeđenih pri koncentracijama većim od prijelazne koncentracije, $c^{*}$.

\subsection{4. koncentrirana otopina (concentrated solution)}

Polimerna otopina u koncentracijskom području pri kojem se domene zauzete otopljenim makromolekulama ili česticama preklapaju u takvoj mjeri da nije moguće međusobno razlikovati pojedine domene.

Napomena: Gornja granica masene koncentracije je gustoća amorfne polimerne tvari.

\subsection{5. prepletaj (u polimernoj znanosti) (entanglement)}

Prepletaj koji uključuje jedan makromolekulski lanac ili više njih, postojan barem tijekom cijelog perioda promatranja.

Napomena: Volumni element u kojem se prepliću lanci dviju ili više makromolekula djeluje kao privremeno spojište promjenjive polimerne mreže, koje kao takvo može postojati u polurazrijeđenoj ili koncentriranoj otopini.

\subsection{6. veličina oka mreže $\mathrm{e}^{\mathrm{p}}$, veličina očice ${ }^{\mathrm{d}}, \xi$, jedinica: $\mathrm{nm}$ ili SI jedinica: $\mathrm{m}$ (u polimernoj znanosti) (mesh size)}

Prosječna udaljenost dvaju susjednih prepletaja na promatranoj makromolekuli u polurazrijeđenoj otopini, koncentriranoj otopini ili amorfnoj polimernoj tvari.

\subsection{7. uzao $(b / o b)$}

Hipotetski sferni volumni element zauzet dijelom lanca između dvaju susjednih prepletaja na istoj makromolekuli.
Napomena 1: Dimenzije uzla ovise o koncentraciji i temperaturi.

Napomena 2: Pretpostavlja se da vladanje pojedinih dijelova makromolekule na udaljenosti koja je veća od dimenzija jednog uzla nije u međusobnoj korelaciji.

\subsection{8. zakon sličnosti (scaling law)}

Jednadžba oblika $y=k x^{a}$ koja povezuje dvije fizikalne veličine, $x$ i $y$, u kojoj se vrijednost eksponenta a može predvidjeti teorijom.

Napomena 1: Konstanta $k$ ne može se predvidjeti teorijom i mora se odrediti eksperimentalno.

Napomena 2: Pokazalo se da su zakoni sličnosti posebice korisni za opis polurazrijeđenih polimernih otopina.

3.1.9. slobodni volumen ${ }^{p}$, slobodni obujam ${ }^{\mathrm{d}}, v_{\mathrm{f}}, \mathrm{SI}$ jedinica: $\mathrm{m}^{3} \mathrm{~kg}^{-1}$ (free volume)

Razlika specifičnog volumena amorfnog polimera i slobodnog volumena savršenog kristalnog oblika istog polimera.

\subsubsection{0. međudjelovanje polimer-otapalo (polymer-solvent interaction)}

Zbroj utjecaja svih međumolekulskih međudjelovanja molekula polimera i otapala u otopini što se odražavaju u vrijednostima Gibbsove i Helmholtzove energije miješanja.

\subsubsection{1. teorija usrednjenog polja (mean-field theory)}

Teorija koja pojednostavljuje teško točno određivanje međudjelovanja u sustavu više tijela do jednostavnijeg, ali približnog određivanja prosječnog efektivnog međudjelovanja jednog tijela sa svojom okolinom.

\subsubsection{Flory-Hugginsova teorija (Flory-Huggins theory) Flory-Huggins-Stavermanova teorija (Flory-Huggins-Staverman theory)}

Statistička termodinamička teorija usrednjenog polja polimernih otopina, koju su prvi neovisno oblikovali Flory, Huggins i Staverman; u njoj se termodinamička svojstva otopine izvode iz jednostavnog koncepta kombinatorne entropije miješanja i reduciranog parametra Gibbsove energije, tzv. $\chi$-parametra.

Napomena: Donekle prilagođeno u odnosu na definiciju u lit. ${ }^{9}$

\subsubsection{3. hi-parametar, $\chi$ (chi parameter) $\chi$-parametar ( $\chi$ parameter) hi-parametar međudjelovanja (chi interaction parameter)}

\section{$\chi$-parametar međudjelovanja}

( $\chi$ interaction parameter)

Numerički parametar Flory-Hugginsove teorije, koji opisuje doprinose nekombinatorne entropije miješanja i entalpije 
miješanja Gibbsovoj energiji miješanja.

Napomena: Donekle modificirano u odnosu na definiciju u lit. ${ }^{9}$

3.1.14. parametar topljivosti (polimera), $\delta$, jedinica: $\mu \mathrm{Pa}^{1 / 2}=\mathrm{J}^{1 / 2} \mathrm{~cm}^{-3 / 2}$ ili SI jedinica: $\mathrm{Pa}^{1 / 2}=\mathrm{J}^{1 / 2} \mathrm{~m}^{-3 / 2}$ [solubility parameter (of a polymer)]

Parametar što se rabi u predviđanju topljivosti neelektrolita (uključujući polimere) u danom otapalu. Za tvar B:

$$
\delta_{\mathrm{B}}=\left(\Delta_{\mathrm{vap}} E_{\mathrm{m}, \mathrm{B}} / V_{\mathrm{m}, \mathrm{B}}\right)^{1 / 2}
$$

gdje je $\Delta_{\mathrm{vap}} E_{\mathrm{m}, \mathrm{B}}$ molarna energija isparavanja pri nultom tla$\mathrm{ku}, \mathrm{a} V_{\mathrm{m}}$ je molarni volumen). ${ }^{3}$

Napomena 1: Za polimere se kao vrijednost parametra topljivosti obično uzima vrijednost parametara topljivosti onog otapala koje daje otopinu najveće intrinzične viskoznosti ili onog otapala koje daje najveći stupanj bubrenja umreženog polimera.

Napomena 2: Za tvar male relativne molekulske mase vrijednost parametra topljivosti najpouzdanije se procjenjuje iz entalpije isparavanja i molarnog volumena.

Napomena 3: Topljivost tvari B može se povezati s kvadratom razlike parametara topljivosti pothlađene kapljevine B i otapala pri promatranoj temperaturi, uzimajući u obzir prikladne korekcije za entropiju miješanja. Tako se vrijednost parametra topljivosti B može procijeniti iz topljivosti Čvrstog B u nizu otapala poznatih parametara topljivosti.

\subsubsection{5. preferirana sorpcija (preferential sorption) selektivna sorpcija (selective sorption)}

Ravnotežna pojava u otopinama polimera u višekomponentnim otapalima te u umreženim polimerima nabubrenima višekomponentnim otapalima; očituje se u različitom sastavu smjese otapala u domenama što sadrže polimer i smjese otapala izvan tih domena, pri čemu su faze različitih sastava u termodinamičkoj ravnoteži§.

§Napomena prevoditelja: Znatnije odstupanje od doslovnog prijevoda uz zadržavanje smisla radi veće jasnoće.

\subsubsection{6. selektivno otapalo (selective solvent)}

Tvar koja je otapalo za barem jednu komponentu polimerne smjese, ili za barem jednu vrstu blokova u blok-kopolimerima ili cijepljenim kopolimerima, a neotapalo ili loše otapalo (vidi definiciju 3.2.5., napomenu 2) za drugu komponentu (druge komponente) ili drugu vrstu (druge vrste) blokova.

\subsubsection{7. sutopljivost (CO-solvency)}

Topljivost polimera u otapalu koje sadržava više od jedne komponente, pri čemu je svaka od komponenata sama po sebi neotapalo za polimer.

\subsubsection{8. sunetopljivost (co-nonsolvency)}

Smanjenje topljivosti polimera u otapalu koje sadržava više od jedne komponente, pri čemu je svaka od komponenata sama po sebi otapalo za polimer.

Napomena: Primjeri sustava u kojem dolazi do suneotapanja su poli( $N$-izopropilakrilamid) u smjesi voda $/$ metanol $^{9}$ i poli(vinil-alkohol) u smjesi dimetilsulfoksid/voda. ${ }^{10}$

\subsection{Razrijeđene otopine}

3.2.1. osmotski tlak, $\Pi, \mathrm{SI}$ jedinica: Pa (osmotic pressure)

Dodatni tlak potreban za održavanje osmotske ravnoteže otopine i čistog otapala, razdvojenih membranom propusnom samo za otapalo:

$$
\Pi=-\frac{R T}{V_{\mathrm{s}}^{\prime}} \ln \mathrm{a}_{\mathrm{s}}
$$

gdje su $V_{s}^{\prime}$ i $a_{s}$ parcijalni molarni volumen, odnosno aktivnost, nestlačivog otapala. ${ }^{3}$

Napomena: Za idealne razrijeđene otopine $\Pi=c R T / M_{\mathrm{n}}$ gdje su otopljene čestice pojedinačno pokretljive molekule, ioni itd., neovisno o njihovoj prirodi, c je masena koncentracija otopljenih tvari, a $M_{n}$ je brojčani prosjek molarne mase otopljenih tvari.

\subsection{2. osmometar (osmometer)}

Uređaj za mjerenje osmotskog tlaka.

\subsection{3. osmometrija (osmometry)}

Mjerenje osmotskog tlaka otopine s pomoću osmometra. Napomena: Osmometrija razrijeđene otopine polimera je apsolutna metoda određivanja brojčanog prosjeka molekulske mase polimera i osmotskih virijalnih koeficijenata otopine.

3.2.4. osmotski virijalni koeficijent, $A_{i}$, gdje je $i=1,2 \ldots$ SI jedinica: $\mathrm{mol} \mathrm{kg}^{-i} \mathrm{~m}^{3(i-1)}$ (osmotic virial coefficient) virijalni koeficijent kemijskog potencijala (virial coefficient of the chemical potential)

Koeficijent u ekspanziji kemijskog potencijala otapala, $\mu_{\mathrm{s} \prime}$ kao reda potencija masene koncentracije, $c$, otopljene tvari, tj.:

$$
\mu_{\mathrm{s}}-\mu_{\mathrm{s}}^{\circ}=-\Pi V_{\mathrm{s}}^{\prime}=-R T V_{\mathrm{s}}^{\prime}\left(A_{1} C+A_{2} C^{2}+A_{3} C^{3}+\ldots\right)
$$

gdje je $\mu_{\mathrm{s}}^{\circ}$ kemijski potencijal otapala u referentnom stanju pri temperaturi sustava i okolnom tlaku, $\Pi$ je osmotski tlak, a $V_{\mathrm{s}}^{\prime}$ je parcijalni molarni volumen otapala. $U$ višekomponentnim otapalima definicija je primjenjiva na bilo koju komponentu otapala.

Napomena 1: Prvi osmotski virijalni koeficijent je recipročna vrijednost brojčanog prosjeka molekulske mase, tj. $A_{1}=1 / M_{n}$. Vrijednosti drugog i viših virijalnih koeficijenata, $A_{2}, A_{3} \ldots$, karakteriziraju međudjelovanja polimer-otapalo i polimer-polimer. 
Napomena 2: U virijalne se koeficijente ponekad uključuje i faktor $R T$, pa se dobiva:

$$
\mu_{\mathrm{s}}-\mu_{\mathrm{s}}^{\circ}=-\Pi V_{\mathrm{s}}{ }^{\prime}=-V_{\mathrm{s}}{ }^{\prime}\left(A_{1}{ }^{\prime} C+A_{2}{ }^{\prime} C^{2}+A_{3}{ }^{\prime} C^{3}+\ldots\right),
$$

gdje je $A_{i}^{\prime}=R T A_{i}$.

Napomena 3: Za određivanje $M_{\mathrm{n}}$ i $A_{2}$ često se $\Pi / \mathrm{c}$ crta kao funkcija $c$, tako da je:

$$
\frac{\Pi}{C}=\left(\frac{\Pi}{C}\right)_{0}\left(1+\Gamma_{2} C+\Gamma_{3} C^{2}+\ldots\right),
$$

gdje je $\left(\frac{\Pi}{C}\right)_{0}=\frac{R T}{M_{\mathrm{n}}}$, a $\Gamma_{\mathrm{i}}=M_{\mathrm{n}} A_{i}$

\subsection{5. termodinamička kvaliteta otapala (thermodynamic quality of solvent)}

kvaliteta otapala (quality of solvent)

Kvalitativna karakterizacija međudjelovanja polimer-otapalo.

Napomena 1: Termodinamička kvaliteta otapala ovisi o Gibbsovoj i Helmholtzovoj energiji miješanja otapala i polimera.

Napomena 2: Otopinu polimera u "dobrom" otapalu karakterizira viša vrijednost drugog osmotskog virijalnog koeficijenta u odnosu na otopinu istog polimera u "lošem" otapalu.

\subsection{6. theta-stanje (theta state) $\theta$-stanje ( $\theta$ state)}

Stanje polimerne otopine za koju je drugi osmotski virijalni koeficijent jednak nuli.

Napomena 1: Po nekim svojstvima, polimerna otopina u theta-stanju podsjeća na idealnu otopinu i theta-stanje može se nazvati pseudoidealnim stanjem. Međutim, otopina u theta-stanju ne smije se poistovjetiti s idealnom otopinom.

Napomena 2: Otapalo u takvoj otopini često se naziva theta-otapalom.

Napomena 3: Pretpostavlja se da je stupanj polimerizacije polimera visok.

Napomena 4: U theta-stanju udaljenosti između parova segmenata u fleksibilnom polimernom lancu slijede Gaussovu raspodjelu i lanac ima neometane dimenzije.

3.2.7. theta-temperatura, $\theta, \mathrm{SI}$ jedinica: $\mathrm{K}$ (theta temperature)

$\boldsymbol{\theta}$-temperatura ( $\theta$ temperature)

Temperatura pri kojoj je polimerna otopina u theta-stanju.

\subsection{8. isključeni volumen segmenta} (excluded volume of a segment) segmentni isključeni volumen (segmental excluded volume)
Volumen iz kojega segment makromolekule u otopini efektivno isključuje sve druge segmente, tj. one koje pripadaju istoj makromolekuli kao i one koji pripadaju drugim makromolekulama.

Napomena: Isključeni volumen segmenta ovisi o termodinamičkoj kvaliteti otapala i nije mjera geometrijskog volumena toga segmenta.

\subsection{9. isključeni volumen makromolekule (excluded volume of a macromolecule)} makromolekulski isključeni volumen (macromolecular excluded volume)

Volumen iz kojeg makromolekula u razrijeđenoj otopini efektivno isključuje sve druge makromolekule.

Napomena: Isključeni volumen makromolekule ovisi o termodinamičkoj kvaliteti otapala i nije mjera geometrijskog volumena te makromolekule.

\subsubsection{0. termodinamički ekvivalentna sfera} (thermodynamically equivalent sphere)

Hipotetska sfera, nepronična drugim termodinamički ekvivalentnim sferama, koja ima isti isključeni volumen kao stvarna, promatrana makromolekula.

\subsubsection{1. ekspanzijski faktor, $\alpha_{r}, \alpha_{s}, \alpha_{D}, \alpha_{\eta}$ (expansion factor)}

faktor ekspanzije lanca (chain expansion factor)

Omjer karakteristične linearne dimenzije makromolekule u promatranom otapalu pri promatranoj temperaturi u odnosu na istu karakterističnu dimenziju u theta-stanju pri istoj temperaturi.

Napomena 1: Najčešće primjenjivani ekspanzijski faktori su: ekspanzijski faktor srednjeg kvadrata udaljenosti krajeva, $\alpha_{r}=\left(\left\langle r^{2}\right\rangle /\left\langle r_{0}{ }^{2}\right\rangle\right)^{1 / 2}$; ekspanzijski faktor srednjeg kvadrata polumjera vrtnje, $\alpha_{s}=\left(\left\langle s^{2}\right\rangle\left\langle\left\langle s_{0}{ }^{2}\right\rangle\right)^{1 / 2}\right.$; ekspanzijski faktor translacijske difuzije, $\alpha_{D}=\left(\left\langle r_{D}^{2}\right\rangle /\left\langle r_{D, \theta}{ }^{2}\right\rangle\right)^{1 / 2}$, gdje je $r_{D}$ ekvivalentni hidrodinamički polumjer u translacijskom difuzijskom tečenju, a $r_{D, \theta}$ je odgovarajući polumjer u theta-stanju pri istoj temperaturi pri kojoj je mjeren $r_{D}$; ekspanzijski faktor intrinzične viskoznosti, $\alpha_{\eta}=\left([\eta] /\left[\eta_{\theta}\right]\right)^{1 / 3}$, gdje je $[\eta]$ intrinzična viskoznost, a $\left[\eta_{\theta}\right]$ je intrinzična viskoznost u theta-stanju pri istoj temperaturi pri kojoj je mjeren $[\eta]$.

Napomena 2: Ekspanzijski faktori definirani s pomoću različitih karakterističnih linearnih dimenzija nisu nužno jednaki niti imaju konstantne relativne vrijednosti kao funkciju relativne molekulske mase.

\subsection{Fazno ponašanje}

\subsection{1. mješljivost (miscibility)}

Sposobnost smjese da tvori jednu fazu u određenom području temperatura, tlakova i sastava. ${ }^{9}$

Napomena 1: Postojanje ili nepostojanje (samo) jedne faze ovisi o kemijskim strukturama, funkcijama raspodjele mo- 
larne mase i molekulskoj konstituciji nazočnih komponenata.

Napomena 2: Postojanje (samo) jedne faze može se potvrditi eksperimentima raspršenja svjetlosti, rendgenskih zraka ili neutrona.

Napomena 3: Za dvokomponentnu smjesu, nužan i dovoljan uvjet postojanja stabilne ili metastabilne ravnoteže (samo) jedne homogene faze je:

$$
\left(\frac{\partial^{2} \Delta_{\text {mix }} G}{\partial \phi^{2}}\right)_{T, p} \geq 0
$$

gdje je $\Delta_{\text {mix }} G$ Gibbsova energija miješanja, a $\phi$ je sastav, obično iskazan volumnim udjelom jedne od komponenata. Granica (spinodala) između (meta)stabilnih i nestabilnih stanja definirana je nultom vrijednošću gornje derivacije (vidi definiciju 3.3.4). Postanu li sastavi dviju konjugiranih (supostojećih) faza jednaki s promjenom temperature ili tlaka, treća se derivacija također izjednačava s nulom (što definira kritično stanje ili kritičnu točku).

Napomena 4: Ako je smjesa termodinamički metastabilna, razmiješat će se nakon prikladne nukleacije (vidi definiciju 3.3.6). Ako je smjesa termodinamički nestabilna, razmiješat će se spinodalnom dekompozicijom ili pak mehanizmom nukleacije i rasta, nakon prikladne nukleacije, uz uvjet da pritom nema znatnih kinetičkih smetnji, poput onih što se pojavljuju u smjesama visoke viskoznosti.

\subsection{2. kritična točka (u polimernoj znanosti) (critical point)}

Točka u izobarnoj ravnini temperatura-sastav binarne smjese gdje sastavi svih supostojećih faza postaju identični. ${ }^{9}$ Napomena 1: Postoji i alternativna, općenitija definicija "kritične točke otopine". ${ }^{3}$

Napomena 2: Ako nije drugačije naglašeno, podrazumijeva se atmosferski tlak.

Napomena 3: U faznomu dijagramu nagib tangente na spinodalu u kritičnoj točki jednak je nuli.

Napomena 4: U kritičnoj se točki susreću binodale i spinodale.

Napomena 5: lako se definicija odnosi striktno na binarne smjese, često se pogrešno primjenjuje i na višekomponenthe smjese.

Napomena 6: Vidi definiciju 3.3.1., napomenu 3.

\subsection{3. binodala (u polimernoj znanosti) (binodal) binodalna krivulja (binodal curve) krivulja koegzistencije $^{\mathrm{n}}$ (coexistence curve)}

Krivulja u izobarnoj ravnini temperatura-sastav neke smjese koja određuje područje sastava i temperature gdje se odvija prijelaz iz potpune mješljivosti komponenata u uvjete gdje su jednofazne smjese metastabilne ili nestabilne. ${ }^{9}$ Napomena: Binodalne sastave definiraju parovi točaka na krivulji ovisnosti Gibbsove energije miješanja o sastavu koji imaju zajedničku tangentu; pri tim sastavima dvije komponente imaju jednake kemijske potencijale u objema fazama.

\subsection{4. spinodala (spinodal)}

$$
\text { spinodalna krivulja (spinodal curve) }
$$

Krivulja u izobarnoj ravnini temperatura-sastav neke smjese koja određuje područje sastava i temperature gdje se odvija prijelaz iz uvjeta gdje su jednofazne smjese metastabilne u uvjete gdje su jednofazne smjese nestabilne te podliježu faznoj separaciji uslijed spinodalne dekompozicije. ${ }^{9}$

Napomena 1: Spinodalnu krivulju binarne smjese određuje geometrijsko mjesto svih stanja za koja vrijedi:

$$
\left(\frac{\partial^{2} \Delta_{\text {mix }} G}{\partial \phi^{2}}\right)_{T, p}=0
$$

gdje je $\Delta_{\text {mix }} G$ Gibbsova energija miješanja, a $\phi$ je sastav, obično iskazan volumnim udjelom jedne od komponenata.

Napomena 2: U nestabilnom području omeđenom spinodalnom krivuljom separacija u fazne domene je spontana, tj. za pokretanje procesa razdvajanja nije potreban nukleacijski korak.

\subsection{5. spinodalna dekompozicija (spinodal decomposition) \\ spinodalno fazno razmješavanje (spinodal phase-demixing)}

Difuzijom ograničeno razdvajanje u fazne domene u smjesi, pokrenuto delokaliziranim koncentracijskim fluktuacijama, do kojeg dolazi u nestabilnom području smjese omeđenom spinodalnom krivuljom.

Napomena 1: Donekle modificirano u odnosu na definiciju u referenciji. ${ }^{9}$

Napomena 2: Vidi definiciju 3.3.4, napomena 1. Do spinodalne dekompozicije dolazi kada je iznos druge derivacije Gibbsove energije prema sastavu manji od nule ${ }^{\S}$.

§Napomena prevoditelja: Definicija u izvorniku (Do spinodalne dekompozicije dolazi kada je magnituda fluktuacija Gibbsove energije prema sastavu jednaka nuli.) očito je pogrešna.

\subsection{6. jezgrenje faznog razdvajanja ${ }^{p}$, nukleacija faznog razdvajanja ${ }^{d}$ (nucleation of phase separation)}

Započinjanje oblikovanja faznih domena zbog postojanja koncentracijske heterogenosti. ${ }^{9}$

Napomena: U metastabilnom području faznog dijagrama (vidi definiciju 3.3.1., napomena 4) fazna separacija započinje jedino jezgrenjem*

\subsection{7. točka zamagljenja (cloud point)}

Točka u izobarnoj ravnini temperatura-sastav binarne ili višekomponentne smjese u kojoj se opaža smanjenje prozirnosti zbog mutnoće uzrokovane faznim razdvajanjem.

Napomena 1: Donekle modificirano u odnosu na definiciju u referenciji. ${ }^{9}$

Napomena 2: Točku zamagljenja obilježava prva pojava mutnoće ili zamagljenja. 
Napomena 3: Do točke zamagljenja može se doći mijenjajući temperaturu ili sastav.

Napomena 4: Točka zamagljenja do koje se dolazi promjenom temperature ovisi o brzini zagrijavanja ili hlađenja.

\subsection{8. krivulja zamagljenja (cloud point curve)}

Krivulja ovisnosti temperature o sastavu određena točkama zamagljenja u dvokomponentnim otopinama različita sastava ${ }^{\S}$, prema lit. ${ }^{9}$.

\$Napomena prevoditelja: Znatnije odstupanje od doslovnog prijevoda, uz zadržavanje smisla, radi veće jasnoće.

\subsection{9. temperatura zamagljenja (cloud-point temperature)}

Temperatura u točki zamagljenja.

\subsubsection{0. donja kritična temperatura otopine, DKTO (lower critical solution temperature, LCST)}

Kritična temperatura ispod koje je smjesa mješljiva pri bilo kojem sastavu. ${ }^{9}$

Napomena 1: DKTO ovisi o tlaku i funkcijama raspodjele molarnih masa polimernih komponenata.

Napomena 2: Za smjesu koja sadrži polimerne komponente, ili je od njih u potpunosti sastavljena, može se raditi o različitim polimerima ili česticama istog polimera različite molarne mase.

Napomena 3: DKTO se nalazi u blizini minimuma krivulje zamagljenja.

Napomena 4: DKTO se opaža u smjesama u kojima se topljivost smanjuje s povišenjem temperature.

Napomena 5: DKTO se nalazi rjeđe nego gornja kritična temperatura otopine. Ne može se objasniti jednostavnim teorijama polimernih otopina, poput Flory-Hugginsove teorije. No postoji u nekoliko parova polimer/otapalo i često u mješavinama polimera.

\subsubsection{1. gornja kritična temperatura otopine, GKTO} (upper critical solution temperature, UCST)

Kritična temperatura iznad koje je smjesa mješljiva pri bilo kojem sastavu. ${ }^{9}$

Napomena 1: Iznad GKTO-a i ispod DKTO-a, ako taj postoji, sustav je jednofazan za sve sastave.

Napomena 2: GKTO ovisi o tlaku i funkcijama raspodjele molarnih masa polimernih komponenata.

Napomena 3: Za smjesu koja sadrži polimerne komponente, ili je od njih u potpunosti sastavljena, može se raditi o različitim polimerima ili česticama istog polimera različite molarne mase.

Napomena 4: GKTO se nalazi u blizini maksimuma krivulje zamagljenja.

Napomena 5: GKTO se opaža u smjesama u kojima se topljivost povećava s povišenjem temperature.

Napomena 6: GKTO postoji kod većine smjesa što sadrže polimer, i može se objasniti jednostavnim teorijama polimernih otopina, poput Flory-Hugginsove teorije.

\subsubsection{2. procjep u mješljivosti (miscibility gap)}

Područje unutar binodalne krivulje na izobarnom faznom dijagramu (ovisnost temperature o sastavu) ili izotermnom faznom dijagramu (ovisnost tlaka o sastavu). ${ }^{9}$

Napomena: Procjep u mješljivosti opaža se pri temperaturama ispod GKTO-a ili iznad DKTO-a. Njegov položaj ovisi o tlaku. U procjepu u mješljivosti opažaju se barem dvije supostojeće faze.

\subsection{Transportna svojstva}

\subsection{1. translacijska difuzija (translational diffusion)}

Proces kojim se uslijed translacijskog Brownova gibanja održava ili obnavlja ravnotežna statistička raspodjela položaja molekula ili čestica u prostoru.

\subsection{2. translacijski koeficijent trenja, $f$}

(u polimernoj znanosti), SI jedinica: $\mathrm{kg} \mathrm{s}^{-1}$ (translational frictional coefficient)

koeficijent trenja (u polimernoj znanosti) (frictional coefficient)

Sila trenja, $F$, po jediničnoj brzini, $u$, koju osjeća izolirano sferno tijelo što se giba u jednom smjeru u viskoznom izotropnom fluidu, tj. $F=f u$.

Napomena 1: Općenitije, $f$ se definira kao tenzor koji povezuje vektorsku silu trenja, $\boldsymbol{F}$, na tijelo u viskoznom fluidu i vektorsku brzinu, $\boldsymbol{u}$, kao $\boldsymbol{F}=\boldsymbol{f} \boldsymbol{u}$. No općenitija definicija nije potrebna u polimernoj znanosti budući da se sva eksperimentalna određivanja translacijskog koeficijenta trenja provode tako da su $F$ i $u$ kolinearne i vrijedi $F=f u$.

Napomena 2: $f$ je povezan s translacijskim difuzijskim koeficijentom, $D$, izoliranog tijela preko Einsteinove jednadžbe $D=k T / f$, gdje je $k$ Boltzmannova konstanta, a $T$ je termodinamička temperatura.

\subsection{3. translacijski difuzijski koeficijent, $D$}

(u polimernoj znanosti), SI jedinica: $\mathrm{m}^{2} \mathrm{~s}^{-1}$ (translational diffusion coefficient)

difuzijski koeficijent (u polimernoj znanosti) (diffusion coefficient)

Konstanta razmjernosti koja, pri jednosmjernom toku čestica B množine $n$, povezuje njihov fluks kroz jediničnu površinu, $J_{n} s$ koncentracijskim gradijentom u smjeru $(x)$ toka, $\mathrm{d}_{\mathrm{B}} / \mathrm{d} x, \mathrm{tj}$. $J_{\mathrm{n}}=-D \mathrm{~d} c_{\mathrm{B}} / \mathrm{d} x$.

Napomena 1: Općenitije ${ }^{3}, D$ se definira s pomoću vektorskog toka čestica B množine $n$, kao konstanta razmjernosti koja povezuje njihov fluks kroz jediničnu površinu, $\boldsymbol{J}_{\mathrm{n}} \mathrm{s}$ koncentracijskim gradijentom, $\nabla C_{\mathrm{B}}$, tj. $\boldsymbol{J}_{\mathrm{n}}=-D \nabla C_{\mathrm{B}}$. No općenitija definicija nije potrebna u polimernoj znanosti budući da se sva eksperimentalna određivanja translacijskog difuzijskog koeficijenta provode u uvjetima jednodimenzijskog toka. 
Napomena 2: Ponekad se za $D$ primjenjuje i jedinica $\mu \mathrm{m}^{2} \mathrm{~s}^{-1}$.

\subsection{4. rotacijska difuzija (rotational diffusion)}

Proces kojim se uslijed rotacijskog Brownova gibanja održava ili obnavlja ravnotežna statistička raspodjela položaja molekula ili čestica u prostoru. ${ }^{10}$

\subsection{5. rotacijski koeficijent trenja, $\zeta$}

(u polimernoj znanosti), SI jedinica: J s

(rotational frictional coefficient)

Zamah, $T$, po jediničnoj kutnoj brzini, $\omega$, potreban za vrtnju tijela oko promatrane osi u viskoznom izotropnom fluidu, tj. $T=\zeta \omega$.

Napomena 1: $\zeta$ se povezuje s rotacijskim difuzijskim koeficijentom, $\Theta$, izoliranog tijela u viskoznom izotropnom fluidu jednadžbom $\Theta=k T / \zeta$, gdje je $k$ Boltzmannova konstanta, a $T$ je apsolutna temperatura.

Napomena 2: Tijelo čiji je oblik opisan glavnim osima, a, $b$ i $c$, različitih duljina ima tri različita rotacijska koeficijenta trenja označena s $\zeta_{a} \zeta_{b}$ i $\zeta_{c}$, koji se odnose na rotaciju oko osi $a, b$ odnosno $c$ i tri različita rotacijska difuzijska koeficijenta, $\Theta_{a}, \Theta_{b}$ i $\Theta_{c}$, gdje vrijedi, za izolirano tijelo u viskoznom izotropnom fluidu, $\Theta_{a}=k T / \zeta_{a \prime} \Theta_{b}=k T / \zeta_{b}$ i $\Theta_{c}=k T / \zeta_{c}$

\subsection{6. rotacijski difuzijski koeficijent, $\Theta$ (u polimernoj znanosti), SI jedinica: $\mathrm{s}^{-1}$ (rotational diffusion coefficient)}

Za rotaciju oko promatrane osi to je konstanta razmjernosti koja povezuje brzinu promjene množinske koncentracije, $C_{B}$, čestica B koje zatvaraju kut $\theta$ u odnosu na smjer $\theta=0$ $s$ diferencijalom udjela čestica po jediničnom volumenu, $f(\theta)$, po $\theta, \mathrm{tj} .,\left(\mathrm{d} c_{\mathrm{B}} / \mathrm{d} t\right)_{\theta}=\Theta \mathrm{d} f(\theta) / \mathrm{d} \theta$.

Napomena: Definicija je preuzeta iz lit. ${ }^{10,11}$ i ekvivalentna je onoj u lit. ${ }^{3}$.

\subsection{7. dvolom pri strujanju kapljevina ${ }^{p}$ (streaming birefringence) \\ birefringencija strujanja $^{\mathrm{n}}$ (flow birefringence)}

Dvolom uzrokovan strujanjem u kapljevinama, otopinama i disperzijama optički anizotropnih, anizometričnih i deformabilnih molekula ili čestica uslijed njihove nenasumične orijentacije.

Napomena: Dvolom pri strujanju može se iskoristiti za određivanje rotacijskih difuzijskih koeficijenata.

\subsection{8. taložni koeficijent ${ }^{\mathrm{p}}$, sedimentacijski koeficijent ${ }^{\mathrm{d}}, s$} (u polimernoj znanosti), SI jedinica: $\mathrm{S}$ (sedimentation coefficient)

Brzina taloženja, $u$, po jediničnom ubrzanju u polju centrifugalne sile, $r \omega^{2}$, gdje je $\omega$ kutna brzina, a $r$ je udaljenost od središta vrtnje. $\mathrm{Tj} ., s=u /\left(r \omega^{2}\right)$.
Napomena 1: Za s se prikladno primjenjuje jedinica $10^{-13} \mathrm{~s}$; naziv jedinice je "svedberg" (Sv). $1 \mathrm{~Sv}=10^{-13} \mathrm{~s}=0,1 \mathrm{ps}$.

Napomena 2: Taloženje se u polimernoj znanosti obično proučava upotrebom ultracentrifuge.

Napomena 3: Molarna masa jednolikog polimera može se odrediti iz mjerenih vrijednosti s i translacijskog difuzijskog koeficijenta, $D$, u razrijeđenoj otopini, s pomoću

$$
\left.M=R T s /\left[1-\bar{v} \rho_{0}\right)\right],
$$

gdje je $R$ opća plinska konstanta, $T$ je termodinamička temperatura, $\bar{v}$ je parcijalni specifični volumen polimera, a $\rho_{0}$ je gustoća otapala. Za polimer nejednolik s obzirom na molarnu masu, određuje se prosječna molarna masa.

\subsection{9. ravnoteža taloženja ${ }^{p}$, ravnoteža sedimentacije ${ }^{d}$ (sedimentation equilibrium)}

Ravnoteža koja se uspostavlja u centrifugalnom polju kada, uslijed povratne difuzije, više nema neto toka bilo koje komponente kroz bilo koju ravninu okomitu na centrifugalnu silu.

Napomena: Pri ravnoteži taloženja tok uslijed taloženja uravnotežen je s tokom u obratnom smjeru zbog koncentracijskog gradijenta nastalog taloženjem.

\subsubsection{0. ravnotežna taložna metoda ${ }^{p}$, ravnotežna sedimentacijska metoda ${ }^{\mathrm{d}}$ (equilibrium sedimentation method) \\ metoda taložne ravnoteže ${ }^{p}$, metoda sedimentacijske ravnoteže ${ }^{d}$ (sedimentation-equilibrium method)}

Eksperimentalna metoda kojom se u ćeliji centrifuge pri ravnoteži taloženja mjeri raspodjela koncentracija otopljene ili dispergirane komponente u razrijeđenoj otopini, odnosno disperziji, a rezultati se interpretiraju putem molarnih masa otopljenih molekulskih vrsta ili odgovarajućih funkcija raspodjele, ili s pomoću jednih i drugih.

\subsubsection{1. metoda brzine taloženja ${ }^{p}$, metoda brzine sedimentacije ${ }^{d}$ (sedimentation-velocity method)}

Eksperimentalna metoda kojom se mjeri brzina (ili brzine) taloženja otopljene ili dispergirane komponente (otopljenih ili dispergiranih komponenti) i rezultati se iskazuju u obliku odgovarajućeg koeficijenta taloženja (sedimentacijskog koeficijenta).

\subsubsection{Archibaldova metoda (Archibald's method)}

Eksperimentalna taložna metoda zasnovana na činjenici da je pri meniskusu te pri dnu ćelije ultracentrifuge tok otopljene tvari kroz ravninu okomitu na radijalni smjer uvijek jednak nuli, pa uvijek vrijede jednadžbe koje karakteriziraju ravnotežu taloženja iako sustav kao cjelina može biti znatno udaljen od ravnoteže taloženja.

Napomena: Nikako se ne preporučuje naziv približavanje ravnoteži taloženja* za Archibaldovu metodu budući da ci- 
jela otopina ili disperzija u ćeliji ultracentrifuge nije ni blizu ravnoteži taloženja.

\subsubsection{3. ravnotežno taloženje u gradijentu gustoće ${ }^{p}$,} ravnotežna sedimentacija u gradijentu gustoće ${ }^{d}$ (equilibrium sedimentation in a density gradient) taložna ravnoteža u gradijentu gustoće ${ }^{p}$, sedimentacijska ravnoteža u gradijentu gustoće ${ }^{d}$ (sedimentation equilibrium in a density gradient)

Ravnotežna taložna metoda u kojoj se upotrebljava višekomponentno otapalo čime se u centrifugalnom polju oblikuje gradijent gustoće.

Napomena: Ravnotežno taloženje u gradijentu gustoće može se primijeniti za određivanje heterogenosti sastava kopolimera.

\subsubsection{4. izopiknički (isopycnic)}

Pridjev koji opisuje komponente u višekomponentnom sustavu koje imaju jednake parcijalne specifične volumene. ${ }^{3}$

\subsubsection{5. relativna viskoznost, $\eta_{\mathrm{r}}$ (relative viscosity)} viskoznosni omjern $^{n}$ (viscosity ratio)

Omjer viskoznosti otopine, $\eta$, i viskoznosti otapala, $\eta_{0}, \mathrm{tj}$.: $\eta=\eta / \eta_{0}$.

\subsubsection{6. prirast relativne viskoznosti, $\eta_{\text {inc }}$ (relative viscosity increment)}

Omjer razlike viskoznosti otopine i otapala i viskoznosti otapala, tj. $\eta_{\text {inc }}=\left(\eta-\eta_{0}\right) / \eta_{0}$. (Za definicije simbola, vidi definiciju 3.4.15.)

Napomena: Nikako se ne preporučuje naziv specifična viskoznost $^{\mathrm{n}}$ za ovu veličinu jer inkrement relativne viskoznosti nema obilježja specifične veličine.

\subsubsection{7. reducirana viskoznost, jedinica: $\mathrm{cm}^{3} \mathrm{~g}^{-1}$ ili SI} jedinica: $\mathrm{m}^{3} \mathrm{~kg}^{-1}$ (reduced viscosity) viskoznosni broj ${ }^{n}$ (viscosity number)

Omjer prirasta relativne viskoznosti i masene koncentracije otopljene tvari, $c, \mathrm{tj} . \eta_{\text {inc }} / C$.

Napomena: $\eta_{\text {inc }} / c$ i veličine u sljedećim definicijama 3.4.18 i 3.4.19. nisu viskoznosni brojevi niti neimenovani brojevi. Nazive treba promatrati kao duboko uvriježena tradicijska imena. Bilo kakva zamjena na osnovi konzistentnog nazivlja unijela bi nepotrebnu zbrku u polimernu literaturu.

3.4.18. inherentna viskoznost, $\eta_{\text {inh, }}$ jedinica: $\mathrm{cm}^{3} \mathrm{~g}^{-1}$ ili SI jedinica: $\mathrm{m}^{3} \mathrm{~kg}^{-1}$ (inherent viscosity)

logaritamski viskoznosni broj ${ }^{n}, \eta_{\ln }$ (logarithmic viscosity number)
Omjer prirodnog logaritma relativne viskoznosti i masene koncentracije otopljene tvari, $c$, tj.:

$$
\eta_{\text {inh }} \equiv \eta_{\ln }=\left(\ln \eta_{\mathrm{r}}\right) / C \text {. }
$$

Napomena: Vidi napomenu u definiciji 3.4.17.

3.4.19. intrinzična viskoznost, $[\eta]$, jedinica $\mathrm{cm}^{3} \mathrm{~g}^{-1}$ ili SI jedinica: $\mathrm{m}^{3} \mathrm{~g}^{-1}$ (intrinsic viscosity)

granični viskoznosni broj ${ }^{\text {n }}$

(limiting viscosity number)

Granična vrijednost reducirane viskoznosti ili inherentne viskoznosti pri beskonačnom razrjeđenju otopljene tvari, tj.:

$$
[\eta]=\lim _{c \rightarrow 0}\left(\eta_{\text {inc }} / c\right)=\lim _{c \rightarrow 0} \eta_{\text {inh }}
$$

Napomena: Vidi napomenu u definiciji 3.4.17.

\subsubsection{Hugginsova jednadžba (Huggins equation)}

Jednadžba koja opisuje ovisnost reducirane viskoznosti, $\eta_{\text {inc }} / C$, razrijeđenih otopina o masenoj koncentraciji otopljene tvari, $C$, prema:

$$
\eta_{\text {inc }} / C=[\eta]+k_{\mathrm{H}}[\eta]^{2} C,
$$

gdje je $k_{\mathrm{H}}$ Hugginsov koeficijent, a $[\eta]$ je intrinzična viskoznost.

\subsubsection{Hugginsov koeficijent, $k_{\mathrm{H}}$ (Huggins coefficient)}

Parametar Hugginsove jednadžbe.

\subsubsection{Kraemerova jednadžba (Kraemer equation)}

Jednadžba koja opisuje ovisnost inherentne viskoznosti, $\eta_{\text {inh, }}$ razrijeđene otopine o masenoj koncentraciji otopljene tvari, prema:

$$
\eta_{\text {inh }}=\left(\ln \eta_{\mathrm{r}}\right) / C=[\eta]+k_{\mathrm{K}}[\eta]^{2} C,
$$

gdje je $k_{\mathrm{K}}$ Kraemerov koeficijent, a $[\eta]$ je intrinzična viskoznost.

\subsubsection{Kraemerov koeficijent, $k_{\mathrm{K}}$ (Kraemer coefficient)}

Parametar Kraemerove jednadžbe.

\subsubsection{Mark-Houwinkova jednadžba (Mark-Houwink equation)}

Mark-Houwink-Kuhn-Sakuradina jednadžba (Mark-Houwink-Kuhn-Sakurada equation)

Jednadžba koja opisuje ovisnost intrinzične viskoznosti polimera o njegovoj molarnoj masi, molekulskoj težinin ${ }^{\text {, }}$, relativnoj molarnoj masi ili relativnoj molekulskoj masi, oblika:

$$
[\eta]=K M_{v}{ }^{a} \text { ili }[\eta]=K M_{r, v}{ }^{a},
$$

gdje su $K$ i a konstante čije vrijednosti ovise o prirodi polimera $\mathrm{i}$ otapala te o temperaturi; $M_{\mathrm{v}}$ je viskoznosni pro- 
sjek molarne mase, a $M_{r, v}$ je viskoznosni prosjek molekulske težinen, viskoznosni prosjek relativne molarne mase ili viskoznosni prosjek relativne molekulske mase.

Napomena 1: Preporučuje se primjena ove jednadžbe s molekulskom težinom ${ }^{n}$, relativnom molarnom masom ili relativnom molekulskom masom radije nego s molarnom masom, jer u posljednjem slučaju konstanta $K$ ima nezgrapne i promjenjive dimenzije koje potječu od necjelobrojne i promjenjive vrijednosti eksponenta a.

Napomena 2: Vrijednosti konstanti $K$ i a ponajprije se određuju pomoću jednolikih polimera različitih relativnih molarnih masa ili polimera uske funkcije raspodjele relativnih molarnih masa.

\subsubsection{5. hidrodinamičko međudjelovanje} (hydrodynamic interaction)

U otopini ili disperziji narušavanje strujanja kontinuuma otapala ili sredstva za dispergiranje oko molekule otopljene tvari, segmenta otopljene makromolekule ili dispergirane čestice zbog nazočnosti drugih molekula otopljene tvari, segmenata ili dispergiranih čestica.

\subsubsection{6. slobodno propustan \\ (free-draining, freely draining)}

Pridjev koji opisuje nesmetano strujanje otapala kroz domenu otopljene makromolekule.

Napomena: Do slobodno propusnoga strujanja dolazi u graničnom slučaju nultog hidrodinamičkog međudjelovanja.

\subsubsection{7. nepropustan (impermeable, non-free-draining)}

Pridjev koji opisuje situaciju kod toka makromolekule u otopini ili dispergirane čestice kada je otapalo ili sredstvo za dispergiranje uslijed hidrodinamičkog međudjelovanja praktički imobilizirano unutar domene makromolekule ili dispergirane čestice te se giba zajedno s otopljenom makromolekulom ili dispergiranom česticom.

\subsubsection{8. djelomično propustan \\ (partial free-draining, partially draining)}

Pridjev koji opisuje situaciju kod toka makromolekule u otopini ili dispergirane čestice kada je, gledajući od ruba prema središtu, otapalo ili sredstvo za dispergiranje unutar domene makromolekule ili dispergirane čestice uslijed hidrodinamičkog međudjelovanja sve čvršće imobilizirano u odnosu na makromolekulu ili dispergiranu česticu.

Napomena: Slobodno propusno i nepropusno ponašanje ekstremni su slučajevi koncepta djelomično propusnog ponašanja.

\subsubsection{9. hidrodinamički ekvivalentna kugla \\ (hydrodynamically equivalent sphere)}

Hipotetska sfera koja osjeća iste sile trenja kao stvarna, promatrana polimerna molekula ili dispergirana čestica te je nepropusna okolnom fluidu i drugim hidrodinamički ekvivalentnim sferama ili dispergiranim česticama koje se nalaze u otopini ili disperziji.

Napomena 1: Koncept hidrodinamički ekvivalentne sfere relevantan je za nepropusno ponašanje makromolekule ili raspršene čestice.

Napomena 2: Veličina hidrodinamički ekvivalentne sfere može se razlikovati za različite vrste gibanja, primjerice molekulsku difuziju ili viskozno tečenje.

\subsubsection{0. ekvivalentni hidrodinamički volumen (equivalent hydrodynamic volume)}

Volumen hidrodinamički ekvivalentne sfere.

Napomena: Molarni ekvivalentni hidrodinamički volumen određen mjerenjima intrinzične viskoznosti, $[\eta]$, je $V_{\eta^{\prime}}$ gdje je $V_{\eta}=[\eta] M / N_{A}, M$ je molarna masa, a $N_{A}$ je Avogadrova konstanta.

\subsubsection{1. ekvivalentni hidrodinamički polumjer (equivalent hydrodynamic radius)}

Polumjer hidrodinamički ekvivalentne sfere.

\subsubsection{Stokesova jednadžba (Stokes equation)}

Za izoliranu otopljenu molekulu ili dispergiranu česticu jednadžba koja povezuje translacijski koeficijent trenja, $f$, s ekvivalentnim hidrodinamičkim polumjerom pri translacijskoj difuziji, $r_{D}$, te $s$ viskoznošću kontinuuma otapala, odnosno sredstva za dispergiranje, $\eta_{0}$, prema:

$$
f=6 \pi \eta_{0} r_{D} .
$$

\subsubsection{Stokes-Einsteinova jednadžba}

(Stokes-Einstein equation)

Za izoliranu otopljenu molekulu ili dispergiranu česticu jednadžba koja povezuje translacijski difuzijski koeficijent, $D$, s ekvivalentnim hidrodinamičkim polumjerom pri translacijskoj difuziji, $r_{D}$, te $s$ viskoznošću kontinuuma otapala, odnosno sredstva za dispergiranje, $\eta_{0}$, prema:

$$
D=k T /\left(6 \pi \eta_{0} r_{D}\right)
$$

gdje je $k$ Boltzmannova konstanta, a $T$ je termodinamička temperatura.

Napomena: Stokes-Einsteinova jednadžba izvodi se kombinirajući Stokesovu jednadžbu s Einsteinovom $D=k T / f$. (Vidi definiciju 3.4.2.)

\subsubsection{Perrinova jednadžba (Perrin equation)}

Za izoliranu otopljenu molekulu ili dispergiranu česticu jednadžba koja povezuje rotacijski difuzijski koeficijent, $D_{\Theta}^{\S}$, s ekvivalentnim hidrodinamičkim polumjerom pri rotacijskoj difuziji, $r_{\Theta}$, te $s$ viskoznošću kontinuuma otapala, odnosno sredstva za dispergiranje, $\eta_{0}$, prema:

$$
D_{\Theta}=k T /\left(8 \pi \eta_{0} r_{\Theta}{ }^{3}\right)^{\S}
$$


gdje je $k$ Boltzmannova konstanta, a $T$ je termodinamička temperatura.

\$Napomena prevoditelja: Čini se da jednadžba u izvorniku sadrži pogrešku.

\subsubsection{5. model ogrlice od perli (pearl-necklace model) model zrna i štapića (bead-rod model)}

Model koji ponašanje otopljenog lanca makromolekule pri tečenju opisuje prikazujući ga kao slobodno povezan slijed zrna, od kojih svako iskazuje hidrodinamički otpor tečenju okolnoga kontinuuma otapala, a povezano je sa sljedećim zrnom krutim štapićem koji ne pruža hidrodinamički otpor.

\subsubsection{Kirkwood-Risemanova teorija (Kirkwood-Riseman theory)}

Teorija, zasnovana na modelu ogrlice od perli, koja opisuje translacijsku difuziju i viskozno tečenje izolirane linearne makromolekule u otopini u theta-stanju i uzima u obzir postupnu promjenu iz slobodno propusnog ponašanja pri nižim molekulskim masama do nepropusnog ponašanja pri višim molekulskim masama.

Napomena: Kirkwood-Risemanova teorija obično se primjenjuje u graničnom slučaju nepropusnog ponašanja gdje u biti povezuje ekvivalentni hidrodinamički radijus s korijenom srednjeg kvadrata neometanog polumjera vrtnje, $\left\langle s_{0}{ }^{2}\right\rangle^{1 / 2}$, prema:

$$
\begin{gathered}
r_{D}=0,675\left\langle s_{\mathrm{o}}{ }^{2}\right\rangle^{1 / 2} \\
\mathrm{i} \\
r_{\eta}=0,256\left\langle\mathrm{~s}_{\mathrm{o}}{ }^{2}\right\rangle^{1 / 2},
\end{gathered}
$$

gdje su $r_{D}$ i $r_{n}$ ekvivalentni hidrodinamički polumjeri pri translacijskoj difuziji, odnosno viskoznom tečenju.

\subsubsection{Flory-Foxova pretpostavka \\ (Flory-Fox assumption)}

Pretpostavka da se Kirkwood-Risemanova teorija može primijeniti na linearne izolirane makromolekule u otopini, neovisno o tome jesu li u theta-stanju.

Napomena: Kirkwood-Risemanove relacije između $r_{D}$ odnosno $r_{\eta}$ i korijena srednjeg kvadrata neometanog polumjera vrtnje, $\left\langle s_{0}{ }^{2}\right\rangle^{1 / 2}$, tada su:

$$
\begin{gathered}
r_{D}=0,675\left\langle s^{2}\right\rangle^{1 / 2}=0,675\left\langle s_{\mathrm{o}}{ }^{2}\right\rangle^{1 / 2} \alpha_{D} \\
\mathrm{i} \\
r_{\eta}=0,256\left\langle\mathrm{~s}^{2}\right\rangle^{1 / 2}=0,256\left\langle\mathrm{~s}_{\mathrm{o}}{ }^{2}\right\rangle^{1 / 2} \alpha_{\eta^{\prime}}
\end{gathered}
$$

gdje su $r_{D}$ i $r_{\eta}$ ekvivalentni hidrodinamički polumjeri pri translacijskoj difuziji, odnosno viskoznom tečenju, a $\alpha_{D}$ i $\alpha_{\eta}$ su odgovarajući ekspanzijski faktori.

\subsubsection{Flory-Foxova jednadžba (Flory-Fox equation)}

Jednadžba koja povezuje intrinzičnu viskoznost, [ $\eta$ ], i molarnu masu, $M$, sa srednjim kvadratom polumjera vrtnje, prema:

$$
[\eta] M=\phi^{\prime}\left\langle s^{2}\right\rangle^{3 / 2},
$$

gdje je $\phi^{\prime}$ parametar čija vrijednost ovisi o raspodjeli molarnih masa, konstituciji makromolekula i ekspanziji lanca.

Napomena 1: $[\eta] M / N_{A}$, gdje je $N_{A}$ Avogadrova konstanta, je ekvivalentni hidrodinamički volumen pri viskoznom tečenju, $V_{\eta^{\prime}}$ uz $V_{\eta}=4 \pi r^{3} / 3$. Stoga je Flory-Foxova jednadžba konzistentna s Kirkwood-Risemanovom teorijom i Flory-Foxovom pretpostavkom. (Vidi napomene u definicijama 3.4.36. i 3.4.37.)

Napomena 2: Za otopinu u theta-stanju, $\Phi^{\prime}$ se označava s $\phi_{\theta}^{\prime}$, a vrijednost mu daje Kirkwood-Risemanova teorija: $\phi_{\theta}{ }^{\prime}=4,22 \cdot 10^{22} \mathrm{~mol}^{-1}$.

Napomena 3: Flory-Foxova jednadžba ponekad se piše preko $\left\langle r^{2}\right\rangle$, srednjeg kvadrata udaljenosti krajeva, umjesto preko $\left\langle s^{2}\right\rangle, \mathrm{uz}$ :

$$
[\eta] M=\Phi\left\langle r^{2}\right\rangle^{3 / 2},
$$

gdje je $\phi=\Phi^{\prime} / 6^{3 / 2}$.

Ova jednakost podrazumijeva da je $\left\langle r^{2}\right\rangle=6\left\langle s^{2}\right\rangle$, što je egzaktno točno samo u theta-stanju. $U$ ovom slučaju vrijedi:

$$
[\eta] M=\phi_{\theta}\left\langle r^{2}\right\rangle^{3 / 2},
$$

gdje je:

$$
\Phi_{\theta}=\Phi_{\theta}{ }^{\prime} / 6^{3 / 2}=2,87 \cdot 10^{21} \mathrm{~mol}^{-1} .
$$

Napomena 4: $\Phi$ se naziva viskoznosnom funkcijom ili Floryjevom funkcijom. Vidi definiciju 3.4.39.

\subsubsection{9. viskoznosna funkcija, $\Phi, \mathrm{SI}$ jedinica: $\mathrm{mol}^{-1}$} (viscosity function)

\section{Floryjeva funkcija (Flory function)}

Koeficijent koji povezuje intrinzičnu viskoznost, srednji kvadrat polumjera vrtnje i molarnu masu lančane makromolekule, prema izrazu:

$$
[\eta]=\phi 6^{3 / 2}\left\langle s^{2}\right\rangle^{3 / 2} / \mathrm{M} .
$$

\subsubsection{0. model zrna i opruge (bead-spring model)}

Model koji ponašanje otopljene lančane makromolekule pri tečenju opisuje prikazujući je kao slobodno povezan slijed zrna, od kojih svako iskazuje hidrodinamički otpor tečenju okolnoga otapala, a povezano je sa sljedećim zrnom oprugom koja ne pruža hidrodinamički otpor, ali koja je odgovorna za elastična i deformacijska svojstva lanca.

\subsubsection{Rouseova teorija (Rouse theory)}

Molekulska teorija za opis dinamike polimernoga lanca na osnovi modela zrna i opruge koja pretpostavlja da zrna (segmenti, odsječci) imaju nulti isključeni volumen i da nema hidrodinamičkog međudjelovanja zrnâ.

\subsubsection{Rouseov lanac (Rouse chain)}

Hipotetski polimerni lanac koji zadovoljava pretpostavke uvedene u Rouseovoj teoriji. 


\subsubsection{3. gmizanje (reptation)}

Zmijoliko kretanje polimernog lanca u polurazrijeđenim ili koncentriranim otopinama ili amorfnoj polimernoj tvari kroz hipotetsku cijev što je oblikuju susjedni lanci.

\subsubsection{4. cijevni model (tube model)}

Model koji opisuje gibanje polimernog lanca zatvorenog u hipotetsku cijev što je oblikuju susjedni polimerni lanci. Napomena 1: U cijevnom modelu polimerni se lanac giba uzduž hipotetske cijevi što je oblikuju susjedni polimerni lanci. Pritom se kontinuirano odvija obnavljanje cijevi.
Napomena 2: Cijevni je model temeljni koncept gmizanja.

\subsubsection{5. obnavljanje cijevi (tube renewal)}

Dinamičko obnavljanje hipotetskih cijevî rasplitanjem i ponovnim preplitanjem polimernih lanaca.

\subsubsection{6. pralanac (primitive chain)}

Polimerni lanac koji pribjegava puzanju uzduž cijevi što je oblikuju susjedni lanci.

Napomena: Lanac se može opisati kao povezani slijed uzlova.

\section{Literatura \\ References}

1. R. G. Jones, J. Kahovec, R. Stepto, E. S. Wilks, M. Hess, T. Kitayama, W. V. Metanomski (ur.), Compendium of Polymer Terminology and Nomenclature, IUPAC recommendations 2008 (the "Purple Book"), RSC Publishing, Cambridge, 2009.

2. P. Kratochvíl, U. W. Suter, Definitions of Terms Relating to Individual Macromolecules, Their Assemblies, and Dilute Polymer Solutions (IUPAC Recommendations 1988), Pure Appl. Chem. 61 (1989) 211-241, doi: https://doi.org/10.1351/ pac198961020211, poglavlje 3 u lit. 1. Hrvatski prijevod: N. Šegudović: Definicije pojmova za pojedinačne makromolekule, njihove skupine i razrijeđene otopine polimera (preporuke IUPAC 1988., preporuke HDKI i HKD 1992.), Kem. Ind. 42(2) (1993) B1-B12.

3. IUPAC, Compendium of Chemical Terminology, 2. izd. (the "Gold Book"), sastavili A. D. McNaught, A. Wilkinson, Blackwell Scientific Publications, Oxford, UK (1997); vidi također: M. Nic, J. Jirat, B. Kosata, XML on-line ispravljena verzija: http://goldbook.iupac.org (2006.-), sadržaj objedinio A. D. Jenkins.

4. A. D. Jenkins, P. Kratochvíl, R. F. T. Stepto, U. W. Suter, Glossary of basic terms in polymer science (IUPAC Recommendations 1996), Pure Appl. Chem. 68 (1996) 2287-2311, doi: https://doi.org/10.1351/pac199668122287, poglavlje 1 u lit. 1. Hrvatski prijevod: V. Jarm, Glosar osnovnih pojmova u znanosti o polimerima (preporuke IUPAC 1996., preporuke HDKI i HKD 1998.), Kem. Ind. 47(12) (1998) B5-B19.

5. P. J. Flory, Statistical Mechanics of Chain Molecules, Interscience Publishers, London, 1969.

6. A. D. Jenkins, Stereochemical definitions and notations relating to polymers (IUPAC Recommendations 1980), Pure Appl. Chem. 53 (1981) 733-752, poglavlje 2 u lit. 1. Hrvatski prijevod: V. Jarm, Z. Smolčić Žerdik, Stereokemijske definicije i oznake koje se odnose na polimere (preporuke IUPAC 1980., preporuke HDKI i HKD 1988.), Kem. Ind. 37(10) (1988) B38-B50.
7. M. G. Kendall, Advanced Theory of Statistics, volumen 1, Charles Griffin, London, 1948.

8. R. F. T. Stepto, Dispersity in polymer science (IUPAC Recommendations 2009), Pure Appl. Chem. 81 (2009) 351-353, doi: https://doi.org/10.1351/PAC-REC-08-05-02; Erratum ibid. 81 (2009) 781, doi: https://doi.org/10.1351/PACREC-08-05-02 erratum. Hrvatski prijevod: M. Rogošić, Disperznost u polimernoj znanosti (preporuke IUPAC 2009., preporuke HDKI i HKD 2012.), Kem. Ind. 61 (5-6) (2012) 305-309.

9. W. J. Work, K. Horie, M. Hess, R. F. T. Stepto, Definitions of terms related to polymer blends, composites, and multiphase polymeric materials (IUPAC Recommendations 2004), Pure Appl. Chem. 76 (2004) 1985-2007, doi: https:// doi.org/10.1351/pac200476111985, poglavlje 9 u lit. 1. Hrvatski prijevod: G. Bogdanić, A. Erceg Kuzmić, R. Vuković, Definicije osnovnih pojmova koji se odnose na polimerne mješavine, kompozite i višefazne polimerne materijale (preporuke IUPAC 2004., preporuke HDKI i HKD 2009.), Kem. Ind. 58(9) (2009) 387-403.

10. A. E. Alexander, P. Johnson, Colloid Science, poglavlje XIV, Oxford University Press, Oxford, 1950.

11. C. Tanford, Physical Chemistry of Macromolecules, poglavlje 6, John Wiley, New York, 1961.

12. B. J. Berne, R. Pecora, Dynamic Light Scattering with Applications to Chemistry, Biology and Physics, John Wiley, New York, 1976.

Ponovno objavljivanje ili reprodukcija ovog izvješća ili njegova pohrana i/ili širenje elektroničkim putem dopuštena je bez formalne IUPAC-ove dozvole uz uvjet jasno vidljivog isticanja izvora, s punom referencijom,

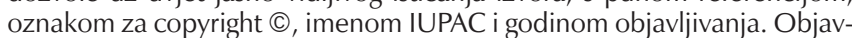
ljivanje prijevoda na drugi jezik podložno je dodatnom uvjetu prethodnoga odobravanja od nadležne nacionalne organizacije pri IUPAC-u. 


\section{SUMMARY}

\section{Definitions of Terms Relating to Individual Macromolecules, Macromolecular Assemblies, Polymer Solutions, and Amorphous Bulk Polymers (Part II) \\ (IUPAC Recommendations 2014) \\ Translated by Marko Rogošić}

This document defines terms relating to the properties of individual macromolecules, macromolecular assemblies, polymer solutions, and amorphous bulk polymers. In the section on polymer solutions and amorphous bulk polymers, general and thermodynamic terms, dilute solutions, phase behaviour, transport properties, scattering methods, and separation methods are considered. The recommendations are a revision and expansion of the IUPAC terminology published in 1989 dealing with individual macromolecules, macromolecular assemblies, and dilute polymer solutions. New terms covering the principal theoretical and experimental developments that have occurred over the intervening years have been introduced. Polyelectrolytes are not included.

\section{Keywords}

Amorphous polymers, bulk polymers, IUPAC Polymer Division, macromolecular assemblies, macromolecules, polymer phase behaviour, polymer solutions, polymer thermodynamics, scattering properties, separation methods, transport properties

University of Zagreb

Faculty of Chemical Engineering and Technology

Nomenclature note

Marulićev trg 19

10000 Zagreb, Croatia

Received November 30, 2015 Accepted May 18, 2016 